\title{
Assessment of Different Methods in Measuring Alveolar Ridge Width Accuracy before Placement of Implant: An In Vivo Study
}

\author{
Naman Awasthi ${ }^{1}$, Aradhana Rathod ${ }^{2}$, Banibrata Lahiri ${ }^{3}$, Deesha Kumari ${ }^{4}$, Sadananda Hota ${ }^{5}$, Shreya Gupta ${ }^{6}$
}

\begin{abstract}
Aim and objective: This study aimed to evaluate the different approaches in measuring alveolar ridge width accurateness before implant placement.

Materials and methods: This study included 30 partially edentulous patients with missing teeth in the age range of 18-50 years needing dental implant prosthetic replacement of the missing teeth. A stent was prepared and the width of the alveolar ridge was estimated employing the following techniques: Group I: Measurement of alveolar ridge width on cone-beam computed tomography (CBCT) method, group II: Measurement of alveolar ridge width by ridge mapping technique, group III: Measurement of alveolar ridge width by surgical exposure. The data were analyzed statistically using the SPSS Statistics for Windows Software, version 17.0. The significance level was set at $5 \%$.

Results: $3.84 \pm 0.20$ was the width of the alveolar ridge on $C B C T, 3.96 \pm 0.44$ with ridge mapping, and $3.78 \pm 0.16$ by direct measurement upon surgical exposure at point 1. The measurements at point 2 on CBCT, by ridge mapping, and on surgical exposure were $6.80 \pm 0.26,7.02 \pm 0.98$, and $6.68 \pm 0.76$, respectively. When ridge mapping and surgical exposure methods at both points were compared, the difference between the groups was significant statistically at point 2 with the $p$ value $<0.04$.

Conclusion: Cone-beam computed tomography and ridge mapping techniques when independently compared with the gold standard surgical exposure system, CBCT was verified to be an extremely specific and sensitive technique to measure the residual alveolar ridge width for dental implant therapy planning.

Clinical significance: Residual ridge resorption following the tooth extraction is an inevitable phenomenon that results in inadequate width of the ridge. Hence, it is essential to measure the physical dimensions of the existing bone as part of the diagnosis and pre-surgical planning before implant placement. The success of the dental implant depends on the significant requirement of dimensions of the existing bone.

Keywords: Alveolar ridge width, Cone-beam computed tomography, Dental implants, Ridge mapping.

World Journal of Dentistry (2021): 10.5005/jp-journals-10015-1870
\end{abstract}

\section{INTRODUCTION}

Dental implant technology has become a dependable therapeutic modality for the replacement of missing teeth in the current times. Nevertheless, implant placement is not a secluded happening; rather it is the outcome of careful planning before surgery to accomplish both the functional and esthetic prospects of patients. The buccolingual osseous ridge dimensions need meticulous assessment to ensure suitable planning of the therapy. ${ }^{1}$

One of the extensively recognized techniques for rehabilitating edentulous areas is the employment of osseointegrated implants. A thorough clinical as well as radiological evaluation is an integral part of therapy planning for implant placement that renders essential data about the position of anatomical structures, the amount and quality of bone that is existing, the existence of bony pathologies, the occlusal form, the size as well as quantity of implants, along with the prosthetic design, each of which is mandatory for the success of implant therapy. ${ }^{2}$

Two-dimensional (2D) imaging modalities which are frequently used, such as intraoral periapical radiographs and orthopantomography have inherent disadvantages such as image distortion and cannot provide a buccolingual view of the ridge, thereby providing information only regarding the bone length, delineation of vessels, and nerves, without rendering
12Department of Dentistry, Government Medical College, Shahdol,
Madhya Pradesh, India
${ }^{2}$ Purna Dental Clinic, Gulbarga, Karnataka, India
${ }^{3}$ Department of Oral and Maxillofacial Surgery, Kalinga Institute of
Dental Sciences, KIIT (Deemed to be University), Bhubaneswar, Odisha,
India
${ }^{4}$ Department of Public Health Dentistry, AB Shetty Memorial Institute
of Dental Sciences, NITTE (Deemed to be University), Mangaluru,
Karnataka, India
${ }^{5}$ Department of Prosthodontics, Kalinga Institute of Dental Sciences,
KIIT (Deemed to be University), Bhubaneswar, Odisha, India
${ }^{6}$ Department of Prosthodontics, Triveni Dental College, Bilaspur,
Chhattisgarh, India
Corresponding Author: Deesha Kumari, Department of Public Health
Dentistry, AB Shetty Memorial Institute of Dental Sciences, NITTE
(Deemed to be University), Mangaluru, Karnataka, India, Phone: +91
9611758152 , e-mail: drdeesha.k@gmail.com

How to cite this article: Awasthi N, Rathod A, Lahiri B, et al. Assessment of Different Methods in Measuring Alveolar Ridge Width Accuracy before Placement of Implant: An In Vivo Study. World J Dent 2021;12(6):474-478.

Source of support: Nil

Conflict of interest: None

() The Author(s). 2021 Open Access This article is distributed under the terms of the Creative Commons Attribution 4.0 International License (https://creativecommons. org/licenses/by-nc/4.0/), which permits unrestricted use, distribution, and non-commercial reproduction in any medium, provided you give appropriate credit to the original author(s) and the source, provide a link to the Creative Commons license, and indicate if changes were made. The Creative Commons Public Domain Dedication waiver (http://creativecommons.org/publicdomain/zero/1.0/) applies to the data made available in this article, unless otherwise stated. 
any evidence of bone width in the potential implant site. The bone width in the buccolingual direction can be assessed using computed tomography (CT), mapping of ridge, ultrasonography, trans-tomography, as well as direct caliper dimension estimation after the bone is surgically exposed. ${ }^{3}$

Dental imaging modalities used in diagnostics have transformed with the advent of cone-beam computed tomography (CBCT). Three-dimensional imaging such as $\mathrm{CBCT}$ renders $3 \mathrm{D}$ volumetric information and reconstruction of dental structures and accompanying maxillofacial areas with significant dimensional accurateness and an isotropic resolution. Cone-beam computed tomography is a form of volumetric radiography with the capability of visualizing the area that has been imaged in practically all planes with moderately less radiation exposure of the patient. ${ }^{4}$

Before the advent of $C B C T$, a substitute technique to determine the characteristics of residual alveolar ridge was ridge mapping. ${ }^{5}$ The gold-standard and highly precise technique to establish the width of the residual alveolar ridge buccolingual is the direct caliper dimension assessment after surgically exposing the bone. Reflecting a flap surgically just to measure the width of the residual ridge following surgical exposure is, however, not justifiable each time for diagnostic and treatment planning purposes for implant placement. To achieve long-term success of dental implants, assessment of the dimensions of the resorbing alveolar ridge must be accurate, because an implant should be surrounded by at least $1 \mathrm{~mm}$ of bone. Careful diagnosis and treatment planning are critical for a favorable outcome. Therefore, the current research was performed to assess and compare ridge mapping and CBCT accurateness for the evaluation of the width of the residual alveolar ridges before the placement of dental implants.

\section{Materials and Methods}

The current clinical research was performed in the Department of Dentistry, Government Medical College, Madhya Pradesh, India. This study included 30 partially edentulous patients with missing teeth in the age range of $18-50$ years needing dental implant prosthetic replacement of the missing teeth. Ethical approval was obtained and informed consent was procured from each patient after informing them about the involved procedures and the design of the research.

The inclusion criteria were individuals $\geq 18$ years of age of either gender with a solitary or several missing teeth in either the maxilla or mandible (Kennedy's Class III) for a minimum period of 6 months following extraction and maintenance of scrupulous oral hygiene, absence of any systemic illness that could impact the normal process of healing or the capability to endure a surgical process like uncontrolled diabetes mellitus, bleeding disorders, history of radiation therapy of the head and neck region or cancer chemotherapy. The exclusion criteria were the existence of acute or chronic infection or local pathologies in the anticipated area of implant placement, parafunctional habits including clenching of teeth as well as severe bruxism, patients with the restricted opening of the mouth to an extent that impedes ease of handling and instrumentation.

\section{Stent Preparation}

Preparation of the stent began with making an impression employing heavy body condensation silicone impression material to make a diagnostic cast. The areas of anticipated implant placement and their distribution were prudently examined on the cast and the reference points were marked on the residual alveolar ridge crest with respect to the adjoining teeth, subsequently, two points were made on the labial aspect and the lingual/palatal side of the ridge, point 1 was made $3 \mathrm{~mm}$ from the reference point while point 2 was marked at $6 \mathrm{~mm}$. Acrylic sheet (Biostar $\left.{ }^{\oplus}\right), 2.0 \mathrm{~mm}$ thick encompassing the reference points, point 1 , point 2 , and some of the adjoining teeth, was utilized to fabricate the surgical stent. Points 1 and 2 could be visualized through the stent past the transparent acrylic resin. Employing a straight fissure bur, guide holes of $1 \mathrm{~mm}$ diameter were drilled with a micro-motor on the crest, buccal, palatal, or lingual aspect. This was followed by condensation of gutta-percha points within the holes until the termination of the tissue surface. Patients were instructed to wear the stent and then a CBCT was taken. Gutta-percha being radiopaque could be visualized on the cone-beam computerized tomography and aided as the radiographic reference area for measurement. The width of the alveolar ridge was measured employing the following techniques in all 30 patients.

\section{Group I: Measurement of Alveolar Ridge Width Based on CBCT Method}

After disinfecting the stent that contained gutta-percha within the guide holes, using povidone-iodine, it was positioned in the patient's oral cavity before procuring the images. Conebeam computed tomography imaging was accomplished with the participants maintaining a supine posture. The exposure parameters included $110 \mathrm{kV}$ and an exposure time in the range of 5.4-9.0 seconds based on the dimensions of the region to be assessed. The selection of the image for measurement was based on the depiction of clear imprints of gutta-percha on the buccal/ lingual sides at the desired points of measurements that is at 3 and $6 \mathrm{~mm}$. The longest distance amid the buccal and lingual bony walls was documented to the closest $0.1 \mathrm{~mm}$ using the software's in-built measurement tool.

\section{Group II: Measurement of Alveolar Ridge Width Based on Ridge Mapping Method}

Subsequently, after local anesthesia administration with $2 \mathrm{~mL}$ disposable syringe-needle, the surgical stent was positioned in the part to be measured, after eliminating gutta-percha from the holes. A calibrated periodontal probe tip was introduced into the guiding holes, piercing through the soft tissues until it contacted bone and the thickness of the soft tissues was estimated. This was followed by sectioning of the diagnostic cast in the edentulous region at right angles to the alveolar ridge at the level of the delineated points. The tissue thickness that was clinically determined was mapped onto these delineated points on the cast thus sectioned employing a pencil, while measuring the width of bone with a scale.

\section{Group III: Measurement of Alveolar Ridge Width Based on Surgical Exposure}

After these two methods, surgical flap reflection was done using a surgical blade as well as a periosteal elevator, and the residual alveolar ridge was subjected to direct measurement of the exposed bone at numerous sites of the guiding holes that were organized employing the same surgical stent with the aid of a bone-caliper. All procedures were performed by two calibrated examiners. The alveolar ridge width of $C B C T$ and ridge mapping method was compared with the surgical exposure method at point 1 and point 2 . 


\section{Statistical Analysis}

The data were analyzed statistically using the SPSS Statistics for Windows Software, version 17.0. The mean as well as standard deviation was estimated employing descriptive statistics. The Student's unpaired " $t$ " test was used for statistical analysis. The significance level was set at $5 \%$.

\section{Results}

Table 1 depicts the descriptive analysis of the width of a residual alveolar ridge at point 1 and point 2. $3.84 \pm 0.20$ was the width of the alveolar ridge on $\mathrm{CBCT}, 3.96 \pm 0.44$ with ridge mapping, and $3.78 \pm 0.16$ by direct measurement upon surgical exposure at point 1 . The measurements at point 2 on $C B C T$, by ridge mapping, and on surgical exposure were $6.80 \pm 0.26,7.02 \pm 0.98$, and $6.68 \pm$ 0.76 in that order.

Table 2 shows the comparative assessment of CBCT and surgical exposure technique at both points 1 and 2. The CBCT measurements were somewhat greater $(3.84 \pm 0.20$ and $6.80 \pm 0.26)$ when compared with the surgical exposure technique $(3.78 \pm 0.16$ and $6.68 \pm 0.76$ ) at both points 1 and 2 . The mean difference at the given points was 0.06 and 0.12 . This difference between the groups was, however, not significant statistically.

Table 1: Mean, standard deviation, and degree of freedom of alveolar ridge width at point 1 and point 2

\begin{tabular}{|c|c|c|c|c|}
\hline Groups & $N$ & $\begin{array}{l}\text { Reference } \\
\text { points }\end{array}$ & Mean $\pm S D$ & $\begin{array}{l}\text { Degree of } \\
\text { freedom }\end{array}$ \\
\hline \multirow{2}{*}{$\begin{array}{l}\text { Group I: Cone-beam } \\
\text { computed tomogra- } \\
\text { phy }(C B C T) \text { method }\end{array}$} & 30 & Point 1 & $3.84 \pm 0.20$ & \multirow[t]{2}{*}{58} \\
\hline & 30 & Point 2 & $6.80 \pm 0.26$ & \\
\hline \multirow{2}{*}{$\begin{array}{l}\text { Group II: Ridge map- } \\
\text { ping method }\end{array}$} & 30 & Point 1 & $3.96 \pm 0.44$ & \multirow[t]{2}{*}{58} \\
\hline & 30 & Point 2 & $7.02 \pm 0.98$ & \\
\hline \multirow{2}{*}{$\begin{array}{l}\text { Group III: Surgical } \\
\text { exposure method }\end{array}$} & 30 & Point 1 & $3.78 \pm 0.16$ & \multirow[t]{2}{*}{58} \\
\hline & 30 & Point 2 & $6.68 \pm 0.76$ & \\
\hline
\end{tabular}

Table 3 delineates the comparative assessment of ridge mapping and surgical exposure technique at both points 1 and 2 . The ridge mapping technique measurements were more (3.96 \pm 0.44 and $7.02 \pm 0.98$ ) when compared with the surgical exposure technique $(3.78 \pm 0.16$ and $6.68 \pm 0.76)$ at both points 1 and 2 . The mean difference at the given points was 0.18 and 0.34 . This difference amid the groups was significant statistically at point 2 with the $p$ value $<0.04$.

Table 4 shows the comparative assessment of CBCT and ridge mapping technique at both points 1 and 2 . The ridge mapping technique measurements were somewhat greater $(3.96 \pm 0.44$ and $7.02 \pm 0.98)$ when compared with CBCT $(3.84 \pm 0.20$ and 6.80 $\pm 0.26)$ at both points 1 and 2 . The mean difference at the given points was -0.12 and -0.22 . This difference between the groups was, however, not significant statistically.

\section{Discussion}

An accurate diagnosis and therapeutic planning are important at every stage of clinical dental practice as it increases the chances of a more foreseeable outcome. The morphological characteristics of the ridge and orientation of the implant are the two significant esthetic and functional reasons for single-tooth restorations that are implant-supported. Residual ridge contour estimation before placing the implant is hence of utmost importance to ensure ideal implant positioning. ${ }^{6}$

The use of radiographic assessment preoperatively has presumed a major role in therapy planning for implant-supported prostheses. The amount and quality of bone affect the implant choice with regard to its diameter, length, form, and number. An orthopantomogram depicts the complete view while intraoral periapical radiographs delineate the height of bone and mesiodistal space in the edentulous region as they are two-dimensional imaging modalities. However, such conventional imaging techniques have the inherent disadvantage of not being able to divulge any details about the sagittal bone morphological characteristics such as ridge

Table 2: Comparison of CBCT method and surgical exposure method at point 1 and point 2

\begin{tabular}{|c|c|c|c|c|c|c|}
\hline Points & Groups & $N$ & Mean $\pm S D$ & $t$ value & $D f$ & $p$ value \\
\hline \multirow[t]{2}{*}{ Point 1} & Group I: CBCT method & 30 & $3.84 \pm 0.20$ & 0.321 & 58 & 0.852 \\
\hline & Group III: Surgical exposure method & 30 & $3.78 \pm 0.16$ & 0.144 & & \\
\hline \multirow[t]{2}{*}{ Point 2} & Group I: CBCT method & 30 & $6.80 \pm 0.26$ & 0.478 & 58 & 0.980 \\
\hline & Group III: Surgical exposure method & 30 & $6.68 \pm 0.76$ & 0.382 & & \\
\hline
\end{tabular}

Table 3: Comparison of ridge mapping method and surgical exposure method at point 1 and point 2

\begin{tabular}{|c|c|c|c|c|c|c|}
\hline Points & Groups & $n$ & Mean $\pm S D$ & tvalue & $D f$ & pvalue \\
\hline \multirow[t]{2}{*}{ Point 1} & Group II: Ridge mapping method & 30 & $3.96 \pm 0.44$ & 0.221 & 58 & 0.612 \\
\hline & Group III: Surgical exposure method & 30 & $3.78 \pm 0.16$ & 0.015 & & \\
\hline \multirow[t]{2}{*}{ Point 2} & Group II: Ridge mapping method & 30 & $7.02 \pm 0.98$ & 0.218 & 58 & 0.04 \\
\hline & Group III: Surgical exposure method & 30 & $6.68 \pm 0.76$ & 0.170 & & \\
\hline
\end{tabular}

Table 4: Comparison of CBCT method and ridge mapping method at point 1 and point 2

\begin{tabular}{|c|c|c|c|c|c|c|}
\hline Points & Groups & $n$ & Mean $\pm S D$ & $t$ value & Df & pvalue \\
\hline \multirow[t]{2}{*}{ Point 1} & Group I: CBCT method & 30 & $3.84 \pm 0.20$ & 0.402 & 58 & 0.718 \\
\hline & Group II: Ridge mapping method & 30 & $3.96 \pm 0.44$ & 0.311 & & \\
\hline \multirow[t]{2}{*}{ Point 2} & Group I: CBCT method & 30 & $6.80 \pm 0.26$ & 0.261 & 58 & 0.514 \\
\hline & Group II: Ridge mapping method & 30 & $7.02 \pm 0.98$ & 0.258 & & \\
\hline
\end{tabular}


width and the implant orientation that would be perfect to fulfill the restorative requirements. ${ }^{7}$

Following the advent of $C B C T$, ridge mapping has become less prevalent for assessing patients requiring implants. However, ridge mapping might still be useful for selected cases as it gives immediate chairside information and has few advantages like simplicity of use and prevention of unnecessary radiation exposure to the patient. ${ }^{8}$

No significant variation between direct surgical exposure and $C B C T$ at either point 1 or 2 was noted in the current study. Additionally, according to this research, $C B C T$ testified as a precise technique to detect the width of residual ridge width when compared with ridge mapping technique in therapy planning for dental implant placement. This, however, is not in agreement with the results of the study by Chen et al. ${ }^{9}$ who found alike measurements in the buccolingual dimension with ridge mapping as well as the use of direct caliper and thus concluded that $\mathrm{CBCT}$ offered no additional diagnostic information pertaining to the area of implant placement. Research by Castro-Ruiz et al. ${ }^{10}$ and Luk et al. ${ }^{11}$ noted that ridge mapping was accurate in measuring the width of residual bone in comparison with various radiographic techniques. Abdel-Wahed et al. ${ }^{12}$ stated that the exactness of diagnostic data found with a $\mathrm{CBCT}$ depends on the way the use of the system and amendment of the attained images.

In this study, significant variation was found amid ridge mapping and surgical exposure technique at point 2 . This is not in harmony with the research by Ten Bruggenkate et al. ${ }^{13}$ who used different ridge-mapping equipment in 176 implant areas in the maxilla, as judged against preoperative dimension estimation (ridge mapping) to dimensions after mucoperiosteal flap reflection (direct caliper measurements) and confirmed that there was no significant difference among the two approaches.

Few studies have nevertheless documented dissimilar results; an average of $3.6 \pm 1 \mathrm{~mm}$ less as compared to the values procured by direct estimation was noted by Perez et al. ${ }^{14}$ This difference was attributed to applying extreme pressure as the caliper points pass through osseous as well as soft tissue that could potentially result in perforating the cortical bone resulting in incorrect calculation of the actual width of the ridge.

A significant variation among both techniques was noted by Allen and Smith ${ }^{15}$ on the contrary as they noticed an inclination toward overvaluing the width of bone, as the caliper may incompletely penetrate the bone through the overlying mucosal tissue especially if the soft tissue thickness is more than that usually present.

Traxler et al. ${ }^{16}$ and Goulet et al. ${ }^{17}$ advocate the ridge mapping technique as it is a suitable and dependable technique to assess the appropriateness of possible implant regions. This method offers the benefits of simplicity of use and prevents unnecessary radiation exposure to the patient.

The results from the current study depict the utility and preciseness of $\mathrm{CBCT}$ in preoperative planning for dental implant placement and also highlight the utility of the ridge mapping method as an easy and economic means for buccolingual residual alveolar ridge width dimension estimation in perfect cases.

Though we minimalized the variables to the best possible extent, certain limitations in the study still exist. Few of these include comparatively small sample sizes and disparities in ethnicities of the participants. Future studies with a bigger sample size and diverse ethnic backgrounds would be desirable to augment and authenticate the present findings.

\section{Conclusion}

Although this study had certain limitations, it could be concluded that $\mathrm{CBCT}$ and ridge mapping techniques when independently compared with the gold standard-surgical exposure system, CBCT was verified to be an extremely specific and sensitive technique to measure the residual alveolar ridge width for dental implant therapy planning. Likewise, it is important to note that ridge mapping could be of use when augmented with conventional radiographic imaging that does not unnecessarily irradiate the patient. It has the advantage of being economical and provides instantaneous results for the width of the alveolar ridge.

\section{References}

1. Simon BI, Von Hagen S, Deasy MJ, et al. Changes in alveolar bone height and width following ridge augmentation using bone graft and membranes. J Periodontol 2000;71(11):1774-1791. DOI: 10.1902/ jop.2000.71.11.1774.

2. Chugh A, Bhisnoi P, Kalra D, et al. Comparative evaluation of three different methods for evaluating alveolar ridge dimension prior to implant placement: an in vivo study. J Dent Implant 2013;3(2):101-110. DOI: 10.4103/0974-6781.118872.

3. Bousquet F, Bousquet $P$, Vazquez L. Transtomography for implant placement guidance in non-invasive surgical procedures. Dentomaxillofac Radiol 2007;36(5):229-233. DOI: 10.1259/ dmfr/91082519.

4. Ghali SR, Katli G, Shahbaz S, et al. Cone beam computed tomography: a boon for maxillofacial imaging. J Indian Acad Oral Med Radiol 2017;29(1):30-34. DOI: 10.4103/jiaomr.JIAOMR_89_16.

5. Mello LA, Garcia RR, Leles JL, et al. Impact of cone-beam computed tomography on implant planning and on prediction of implant size. Braz Oral Res 2014;28(1):46-53. DOI: 10.1590/s180683242013005000029.

6. Chatzistavrianou D, Wilson PH, Taylor P. A guide to implant dentistry part 1: treatment planning. Dent Update 2019;46(5):412-425. DOI: 10.12968/denu.2019.46.5.412.

7. Dave $\mathrm{BH}$, Sutaria $\mathrm{S}$, Mehta $\mathrm{S}$, et al. A comparative study of three different methods for evaluating width of alveolar ridge prior to implant placement: an in vivo study. Int J Oral Care Res 2017;5(1):5360. DOI: $10.5005 /$ jp-journals-10051-0082.

8. Cortes AR, Gomes AF, Tucunduva MJ, et al. Evaluation of linear tomography and cone beam computed tomography accuracy in measuring ridge bone width for planning implant placement. Braz J Oral Sci 2012;11(2):116-119.

9. Chen LC, Lundgren T, Hallström H, et al. Comparison of different methods of assessing alveolar ridge dimensions prior to dental implant placement. J Periodontol 2008;79(3):401-405. DOI: 10.1902/ jop.2008.070021.

10. Castro-Ruiz CT, Noriega J, Guerrero ME. Validity of ridge mapping and computed tomography in dental implant therapy. J Indian Soc Periodontol 2015;19(3):290-293. DOI: 10.4103/0972-124X.154189.

11. Luk LC, Pow EH, Li TK, et al. Comparison of ridge mapping and cone beam computed tomography for planning dental implant therapy. Int J Oral Maxillofac Implants 2011;26(1):70-74.

12. Abdel-Wahed NA, Hamdy RM, Abdel-Latif ZA. Measurements of jaw bones for implant site assessment using cone-beam computed tomography: interobserver and intraobserver agreement. Egypt J Oral Maxillofac Surg 2012;3(2):62-69. DOI: 10.1097/01. OMX.0000418694.73046.c1.

13. Ten Bruggenkate CM, de Rijcke TB, Kraaijenhagen HA, et al. Ridge mapping. Implant Dent 1994;3(3):179-182. DOI: 10.1097/00008505199409000-00008. 
14. Perez LA, Brooks SL, Wang HL, et al. Comparison of linear tomography and direct ridge mapping for the determination of edentulous ridge dimensions in human cadavers. Oral Surg Oral Med Oral Pathol Oral Radiol Endod 2005;99(6):748-754. DOI: 10.1016/j.tripleo.2004. 10.023.

15. Allen F, Smith DG. An assessment of the accuracy of ridge mapping in planning implant therapy for the anterior maxilla. Clin Oral Implants Res 2000;11(1):34-38. DOI: 10.1034/j.1600-0501.2000.011001034.x.
16. Traxler M, Ulm C, Solar $\mathrm{P}$, et al. Sonographic measurement versus mapping for determination of residual ridge width. J Prosthet Dent 1992;67(3):358-361. DOI: 10.1016/0022-3913(92)90246-7.

17. Goulet SV, Fortin T, Thierry A. Accuracy of linear measurement provided by cone beam computed tomography to assess bone quantity in the posterior maxilla: a human cadaver study. Clin Implant Dent Relat Res 2008;10(4):226-230. DOI: 10.1111/j.17088208.2008.00083.x. 